\title{
Agenda legislativa sobre datos personales en Chile
}

\author{
Daniel Álvarez Valenzuela \\ Editor, Revista Chilena de Derecho y Tecnología
}

Luego de casi dos décadas, finalmente se están alcanzado altos grados de consenso en Chile sobre la necesidad de contar con un moderno régimen de protección de datos personales, que, por una parte, incremente la protección efectiva de los derechos de los titulares y, por otra, cuente con las flexibilidades necesarias para permitir un flujo de información personal en los diversos ámbitos de la vida social, comercial, e incluso política, sin desmedro de esos derechos.

El debate doctrinario que ha antecedido este consenso materializado en la discusión en el Congreso Nacional del proyecto de ley sobre datos personales (boletines 11.144 y 11.092, refundidos) ha sido desarrollado, principalmente, en las páginas de la Revista Chilena de Derecho y Tecnología, que, con la presentación de este número, el primero del año 2019, cumplirá siete años de publicación ininterrumpida.

Una revisión somera de los contenidos publicados en estos años da cuenta de que la protección de datos personales ha sido un elemento central, si no el principal, de la preocupación de investigadores e investigadoras del derecho y la tecnología en Chile.

Sin ningún orden en particular, es posible identificar un número importante de artículos que analizan el contenido normativo del proyecto de ley en discusión en el Senado, como lo hace Manuel Vergara en su contribución titulada «Chile: Comentarios preliminares al proyecto de ley que regula la protección y tratamiento de datos personales y crea la Agencia de Protección de Datos Personales», publicado en el volumen 6, número 2 de 2017.

Uno de los temas centrales en el debate legislativo es el concepto de fuente accesible al público como habilitante para el tratamiento de datos personales sin consentimiento del titular, cuya delimitación es esencial para construir un régimen más o menos estricto de protección de datos personales, cuestión que es analizada por Francisco Alvarado en su artículo «Las fuentes de acceso público a datos personales», publicado en el volumen 3, número 2 de 2014.

Sobre el consentimiento como habilitante para el tratamiento de datos personales, es imposible tener una buena discusión sin leer previamente al destacado académico norteamericano Daniel Solove, profesor de George Washington University Law 
School, en particular su artículo sobre «Autogestión de la privacidad y el dilema del consentimiento» que hemos traducido y publicado en el volumen 2, número 2 de 2013.

El tratamiento de datos personales en la administración del Estado y el derecho de acceso a la información pública también forman parte del debate legislativo, y en nuestras páginas hemos publicado dos interesantes artículos que intentan hacerse cargo de esa relación. El primero de ellos hace una contribución específica sobre el equilibro que debe existir entre la Ley de Transparencia y Acceso a la Información Pública y la Ley de Protección de Datos, escrito por Jéssica Matus y publicado en el volumen 2, número 1 de 2013; y, el segundo, de Renato Jijena, analiza el tratamiento de datos personales en el Estado, identificando su protección legal como una limitante al derecho de acceso a la información administrativa, y fue publicado en el volumen 2, número 2 de 2013.

En los debates particulares que el proyecto de ley ha generado, resulta interesante analizar cómo la regulación de la biometría debe ser parte del núcleo protectivo de la futura nueva ley. Sobre este punto, Sebastián Becker y Romina Garrido presentaron un análisis descriptivo de los riesgos que este tipo de tecnologías suponen para la vida privada y la protección de datos personales de sus titulares, publicado en el volumen 6, número 1 de 2017.

Otro de los debates particulares del proyecto de ley consiste en la implementación local del derecho al olvido. La abogada Ana María Muñoz se hizo cargo de la problemática del establecimiento de una obligación general de eliminación de datos personales en internet, con los parámetros que establece la ley vigente sobre protección de datos personales, publicado en el volumen 4, número 2 de 2015.

Un debate que ha estado ausente entre nosotros, sin perjuicio de su importancia para la construcción de un sistema nacional de protección de la ciberseguridad, es el de la problemática relación entre la internet de las cosas y la protección de la privacidad y la protección de datos personales. Un brillante artículo de Paula Jervis describe y analiza esa relación y fue publicado en el volumen 4, número 2 de 2015.

Finalmente, desde una óptica distinta, Catalina Frigerio nos propuso una mirada desde el análisis económico del derecho de los mecanismos de regulación de datos personales, cuestión que el legislador debiera tomar en cuenta en este proceso legislativo. Fue publicado en el volumen 7, número 2 de 2018.

Todas estas contribuciones han tenido por objeto visibilizar aquellas dimensiones del sistema de protección de datos personales que requieren de una discusión y decisión legislativa que permitan contar un sistema robusto de protección de este importantísimo derecho fundamental. 


\title{
REVISTA CHILENA DE DERECHO Y TECNOLOGÍA
}

La Revista de Chilena de Derecho y Tecnología es una publicación académica semestral del Centro de Estudios en Derecho Informático de la Facultad de Derecho de la Universidad de Chile, que tiene por objeto difundir en la comunidad jurídica los elementos necesarios para analizar y comprender los alcances y efectos que el desarrollo tecnológico y cultural han producido en la sociedad, especialmente su impacto en la ciencia jurídica.

\author{
EDITOR GENERAL \\ Daniel Álvarez Valenzuela \\ (dalvarez@derecho.uchile.cl) \\ SITIO WEB \\ rchdt.uchile.cl \\ CORREO ELECTRÓNICO \\ rchdt@derecho.uchile.cl \\ LICENCIA DE ESTE ARTÍ́CULO \\ Creative Commons Atribución Compartir Igual 4.o Internacional
}

\begin{abstract}
La edición de textos, el diseño editorial
y la conversión a formatos electrónicos de este artículo

estuvieron a cargo de Tipográfica

(www.tipografica.cl).
\end{abstract}

